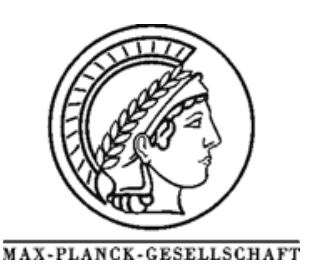

\title{
Methylcyclopropane reactions on $\mathrm{Rh}-\mathrm{Ge} / \mathrm{Al}_{2} \mathrm{O}_{3}$ catalysts prepared by controlled surface reaction
}

\author{
D. Teschner ${ }^{1}$, L. Pirault-Roy ${ }^{2}$, D. Naud ${ }^{2}$, M. Guérin ${ }^{2}$, Z. Paál ${ }^{1}$ \\ ${ }^{1}$ Institute of Isotope and Surface Chemistry, Chemical Research Center, Hungarian Academy of Sciences, \\ P.O.B. 77, Budapest H-1525, Hungary \\ ${ }^{2}$ LACCO, UMR-CNRS 6503, Faculté des Sciences, Université de Poitiers, 40 Avenue du Recteur Pineau, 86022 \\ Poitiers Cedex, France
}

* Corresponding author: e-mail teschner@iserv.iki.kfki.hu, fax:(+36) 13922533

\begin{abstract}
The reaction mechanism of methylcyclopentane (MCP) ring opening on Rh catalysts (the participation of each intermediate in further hydrogenolysis vs. their desorption) was studied on a special series of $\mathrm{Rh}(\mathrm{Ge}) / \mathrm{Al}_{2} \mathrm{O}_{3}$ catalysts. These were obtained by wet impregnation and adding different amounts of Ge by anchoring of $\mathrm{Ge}\left(\mathrm{n}-\mathrm{C}_{4} \mathrm{H}_{9}\right)_{4}$ on the surface of Rh with preadsorbed hydrogen. As shown earlier [1], low amounts of Ge were deposited selectively on low-Miller-index microfacets, whereas excess use of $\mathrm{Ge}\left(\mathrm{n}-\mathrm{C}_{4} \mathrm{H}_{9}\right)_{4}$ caused statistical deposition on Rh. This difference was also reflected in the ring-opening pattern: the sample with randomly located Ge behaved like the parent catalyst with dispersion of $80 \%$. Each ring-opening intermediate hydrogenolyzed further nearly to the same extent; the ring opening product distribution (ROPD) showing thus no variation as a function of reaction conditions. The catalyst with selective Ge deposition followed, however, the pattern of a sintered sample: the surface intermediate of 2-methylpentane underwent preferential hydrogenolysis to smaller fragments. Thus, changing the position of Ge deposits (without modifying the particle size) induced changes in the prevailing reaction route.
\end{abstract}

Keywords: Rh and Rh-Ge catalysts, Tailor-made catalysts, MCP ring opening

\section{Introduction}

Tailor-made catalysts, including bimetallic systems have great scientific as well as industrial importance. Their complete characterization should combine physical methods (e.g. electron microscopy or spectroscopy) and appropriate test reactions. We studied [1] Rh-Ge/Al2O3 catalysts by infrared (IR) spectroscopy of chemisorbed CO, H2 chemisorption and transmission electron microscopy (TEM). These results showed that he deposition of Ge on to $\mathrm{Rh}$ was selective: it occurred first on low Miller-index planes, when low amounts of Ge (less than 0.1 wt.\%) were added to $\mathrm{Rh} / \mathrm{Al} 2 \mathrm{O} 3$. More Ge covered the $\mathrm{Rh}$ surface in a random way. The presence and location of Ge had a strong influence on the reactions of 2,2,3-trimethylbutane. Selective Ge deposition hampered multiple hydrogenolysis.

One of the best methods to achieve "selective" deposition of $\mathrm{Ge}$ on the $\mathrm{Rh}$ sites is the use of "surface organometallic chemistry” [2,3,4,5]. Our catalysts [1] were prepared by introducing $\mathrm{Ge}\left(\mathrm{n}-\mathrm{C}_{4} \mathrm{H}_{9}\right)_{4}$, to a hydrogen- covered $\mathrm{Rh} / \mathrm{Al}_{2} \mathrm{O}_{3}$. The present paper reports on the testing of $\mathrm{Rh}-\mathrm{Ge} / \mathrm{Al}_{2} \mathrm{O}_{3}$ samples by another catalytic reaction, using a cyclic model hydrocarbon: methylcyclopentane (MCP), widely used in metal catalysis as a probe molecule $[6,7]$. When the support is non-acidic and the reaction is carried out at low temperature, hydrogenative "ring opening” prevails. The product distribution of this reaction depended on the nature of the metal [8], on its surface structure $[9,10]$, on possible non-stoichiometric surface components [11,12], and also on the reaction conditions $[13,14]$. Kramer et al. $[15,16]$ attributed the "non-selective" ring opening to "adlineation sites" i.e. to ensembles at the metal-support borderline, whereas selective ring opening would involve pure metallic sites.

Rhodium catalysts are much less sensitive to the metallic dispersion in the conversion of MCP [7,17,18,19]. The reaction conditions may have exerted more significant effect on the product distribution than particle size $[7,14,20]$ : as the temperature increased and the hydrogen excess decreased, multiple hydrogenolysis - yielding $<\mathrm{C}_{6}$ 
fragments - became more and more important. The 2methylpentane to n-hexane ratio $(2 \mathrm{MP} / \mathrm{nH})$ also decreased when the dispersion of the catalysts was not higher than 60$70 \%$. Over Rh catalysts of lower dispersion ( $\mathrm{D}<60-70 \%$ ), the position of the first $\mathrm{C}-\mathrm{C}$ bond breaking was independent of the reaction conditions. The probability of rupture was as follows:

$$
\text { "a (nH)" < "b (2MP)" = "c (3MP)" }
$$

The desorption of surface 2MP intermediate: "2MPS" was hindered. Instead, this intermediate underwent further hydrogenolysis and produced fragments. These secondary reactions changed the $2 \mathrm{MP} / \mathrm{nH}$ ratio. The desorption hindrance was corroborated by the fragmentation pattern of open-chain $\mathrm{C}_{6}$ isomers. Their combination could model the fragmentation pattern of MCP [21,22]. In the case of well-dispersed catalysts ( $\mathrm{D}>60-70 \%$ ) the probability of the ring-opening surface intermediates to undergo further hydrogenolysis was random. Thus, the ratio of $2 \mathrm{MP} / \mathrm{nH}$ was rather low $(\sim 3)$ and independent of the reaction conditions.

To examine the "changeover" between the two behaviors, Rh-Ge/ $/ \mathrm{Al}_{2} \mathrm{O}_{3}$ catalysts of Ref. [1] were tested in the conversion MCP. This way we could identify the role of different coordination sites in the reaction mechanisms without modifying the particle size. By different deposition of an inactive metal, Ge, special rhodium sites were blocked and in this way alteration in the reaction mechanism was induced.

\section{Experimental}

\section{Catalysts}

All catalysts had a Rh loading of $1 \mathrm{wt} \%$ and were supported on alumina from Degussa (Aluminum Oxid C, $\delta$ alumina, surface area of $100 \mathrm{~m}^{2} . \mathrm{g}^{-1}$, grain sizes 0.1 to 0.25 $\mathrm{mm}$ ). The Parent catalyst prepared by wet impregnation of the support by the rhodium salt of $\mathrm{Rh}\left(\mathrm{NO}_{3}\right)_{3}$ had a dispersion of $80 \%$. Different bimetallic catalysts were prepared: Ge $1 / 2$ and Ge 2 denotes the (nominal) amount of added Ge expressed as monolayer coverage. The preparation procedure itself (without $\mathrm{Ge}$ ) resulted in slight sintering (Blank catalyst). Details of preparation - by using the surface organometallic chemistry method, i. e., anchoring $\mathrm{Ge}(\mathrm{n}-$ $\left.\mathrm{C}_{4} \mathrm{H}_{9}\right)_{4}$ on the surface of hydrogen-covered rhodium particles under inert atmosphere - and pretreatments have been published earlier [1]. The dispersion of samples were: Parent: $80 \%$, Blank, 60\%, Ge 1/2: 64\%, Ge2 65\%.

\section{Catalytic tests}

The conversion of methylcyclopentane was studied in a closed-loop apparatus at a standard MCP pressure of 10 Torr $(1$ Torr $=0.133 \mathrm{kPa}$ ) and various hydrogen pressures (120-480 Torr). The reaction temperature ranged from 468 to $513 \mathrm{~K}$. Other details - analysis, data processing etc. - can be found in earlier publications $[1,7]$. The term “ring-opening products” (ROP) is used for saturated $\mathrm{C}_{6}$ products, while "fragments" mean $<\mathrm{C}_{6}$ hydrocarbons.

\section{Results}

As shown by TEM, practically no sintering occurred when Ge was introduced into the catalysts. Comparing the bimetallic catalysts to the Parent one, the decrease of accessibility (about $20 \%$ ) evaluated by $\mathrm{H}_{2}$ chemisorption was explained by $\mathrm{Ge}$ poisoning of surface Rh atoms. Indeed, a loading of 1500 ppm Ge would block one-fifth of Rh surface atoms on the basis of one inactive Ge atom covering one Rh atom. Such a blocking leads to a loss of accessibility estimated to be $20 \%$, very similar to the measured value. Ge can be selectively deposited on Rh as demonstrated by CO FTIR measurements [1]. The selectivity of the deposition was related to the initial amount of Ge in the solution used for the grafting. If the Ge quantity was too large, the Ge deposition seemed to be more or less random, as described in previous works [2,23]. If low amount of Ge was grafted in our conditions of preparation, the preferential locations were the high-coordination sites of the Rh surface.

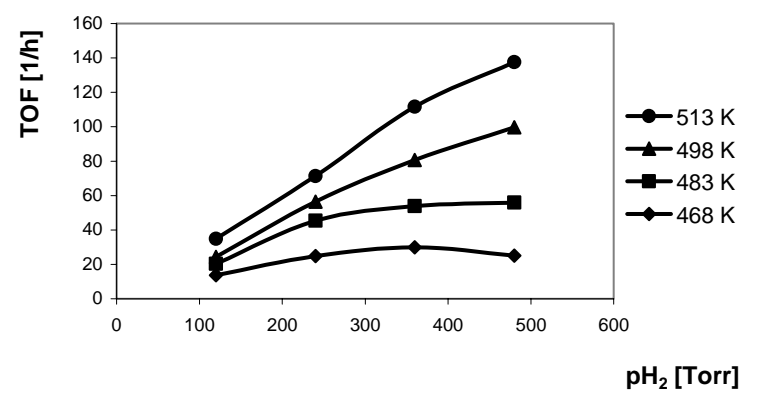

Figure 1: Turnover frequencies for the conversion of methylcyclopentane (MCP) on the Parent catalyst as a function of hydrogen pressure at four different temperatures.

Figure 1 shows the turnover frequencies for the Parent monometallic catalyst as a function of hydrogen pressure at four different temperatures. As a rule, positive hydrogen order was observed. Maximum rates characteristic for hydrocarbon conversion on metals [11,24] were reached in our hydrogen pressure range almost exclusively at the lowest temperature. Similar tendencies appeared on the two $\mathrm{Rh} / \mathrm{Al}_{2} \mathrm{O}_{3}$ and two $\mathrm{Rh}-\mathrm{Ge} / \mathrm{Al}_{2} \mathrm{O}_{3}$ catalysts at a selected temperature of $498 \mathrm{~K}$ (Figure 2a). Sample Ge 1/2 seemed to be most active. The fragment $\left(<\mathrm{C}_{6}\right)$ selectivities decrease at higher hydrogen pressures (Figure $2 \mathrm{~b}$ ). As opposed to the uniform activity patterns, the selectivities can be separated into two groups: Parent and Ge2 produced more fragments by about $10 \%$ than Blank and Ge 1/2. Accordingly, the selectivity of ring opening for the latter two increased to the same extent. The agreement between the selectivities is quite remarkable. Taking into account the negligible alteration in the particle morphology caused by the Ge deposition and the agreement between S(Parent) and $\mathrm{S}(\mathbf{G e} 2)$ and between $\mathrm{S}\left(\right.$ Blank) and $\mathrm{S}\left(\mathbf{G e} \frac{1 / 2}{2}\right)$, the $10 \%$ 
change in the reaction selectivity is significant. Although small amounts of benzene and traces of 1methylcyclopentene appeared at high temperatures, we devote our attention to the two main reactions, to the single and multiple breaking of $\mathrm{C}-\mathrm{C}$ bonds (ROP and fragments).

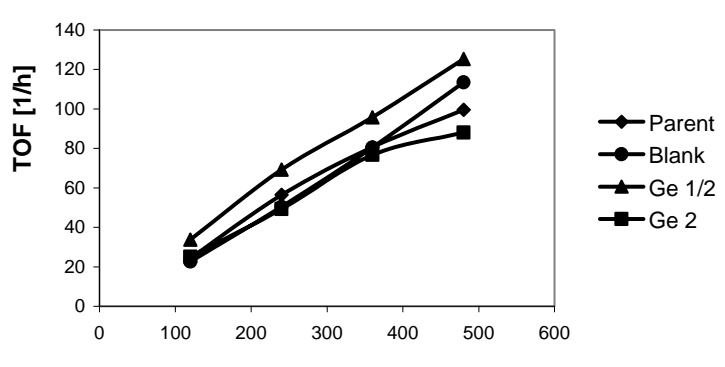

$\mathrm{pH}_{2}[\mathrm{Torr}]$

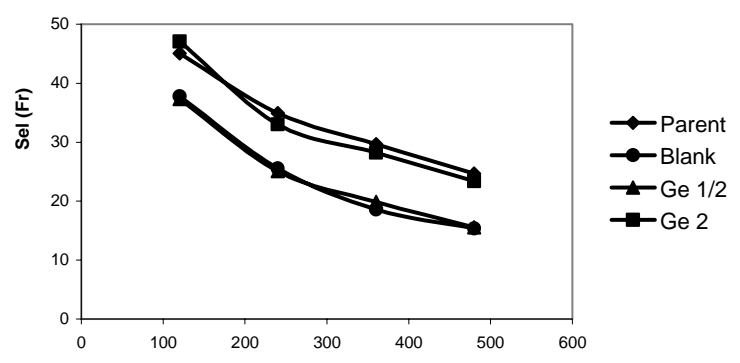

$\mathrm{pH}_{2}$ [Torr]

Figure 2: (a) Turnover frequencies and (b) fragmentation selectivities in the conversion of methylcyclopentane on Rh and $\mathrm{Rh}-\mathrm{Ge} / \mathrm{Al}_{2} \mathrm{O}_{3}$ catalysts as a function of hydrogen pressure. $\mathrm{T}=498 \mathrm{~K}$.

The ring opening of MCP occurred "selectively"; i.e. the rupture in the vicinity of the methyl group was hindered. Thus mainly the mono-branched hexane isomers (2methylpentane and 3-methylpentane) were formed. Table 1 displays the $2 \mathrm{MP} / \mathrm{nH}$ ratio measured at different hydrogen pressures, characteristic of the distribution of ring-opening products. The same classification is valid as in Figure 2b: Parent and Ge2 showing constant and low ratios, while the $2 \mathrm{MP} / \mathrm{nH}$ increased at higher $p\left(\mathrm{H}_{2}\right)$ values the other two samples (Blank and Ge 1/2). The two Rh-Ge catalysts behaved differently, although their dispersion and the Ge loading were similar.

Table 1: Ratio of 2-methylpentane to n-hexane (2MP/nH) on four catalysts, as a function of the hydrogen pressure. $\mathrm{T}=483 \mathrm{~K}$.

\begin{tabular}{|l|l|l|l|l|}
\hline$p\left(\mathrm{H}_{2}\right)$, Torr & 0 & Catalyst & & \\
\hline & Parent & Blank & Ge $\frac{1 / 2}{2}$ & Ge 2 \\
\hline 120 & 2.99 & 3.22 & 3.17 & 2.90 \\
\hline 240 & 2.97 & 3.39 & 3.47 & 2.88 \\
\hline 360 & 2.94 & 3.58 & 3.71 & 2.86 \\
\hline 480 & 2.94 & 3.81 & 3.84 & 2.84 \\
\hline
\end{tabular}

Figure 3 compares the selectivities of the three ringopening products and that of $2 \mathrm{MP}+$ fragments on two $\mathrm{Rh}$ Ge catalysts as a function of reaction conditions [7,14,22]. Two patterns appeared. On Ge 1/2, the constant selectivities of $\mathrm{nH}, 3 \mathrm{MP}$ and $2 \mathrm{MP}+$ fragments suggest that (i), most fragments must have been produced from the 2MP surface ring-opening intermediate $\left(2 \mathrm{MP}_{\mathrm{S}}\right)$ and (ii), the probability of the first $\mathrm{C}-\mathrm{C}$ bond breaking in a given position is independent of the reaction conditions. This pattern was observed on a low-dispersion $10 \% \mathrm{Rh} / \mathrm{Al}_{2} \mathrm{O}_{3}$ catalyst [7] and also on our Blank catalyst. On Ge 2, the selectivities of $\mathrm{nH}$, $3 \mathrm{MP}$ and 2MP change in a parallel way (Figure 2b). Thus, all three primary $\mathrm{C}_{6}$ surface intermediates of ring-opening reacted further to produce fragments. This behavior appeared also on the Parent catalyst
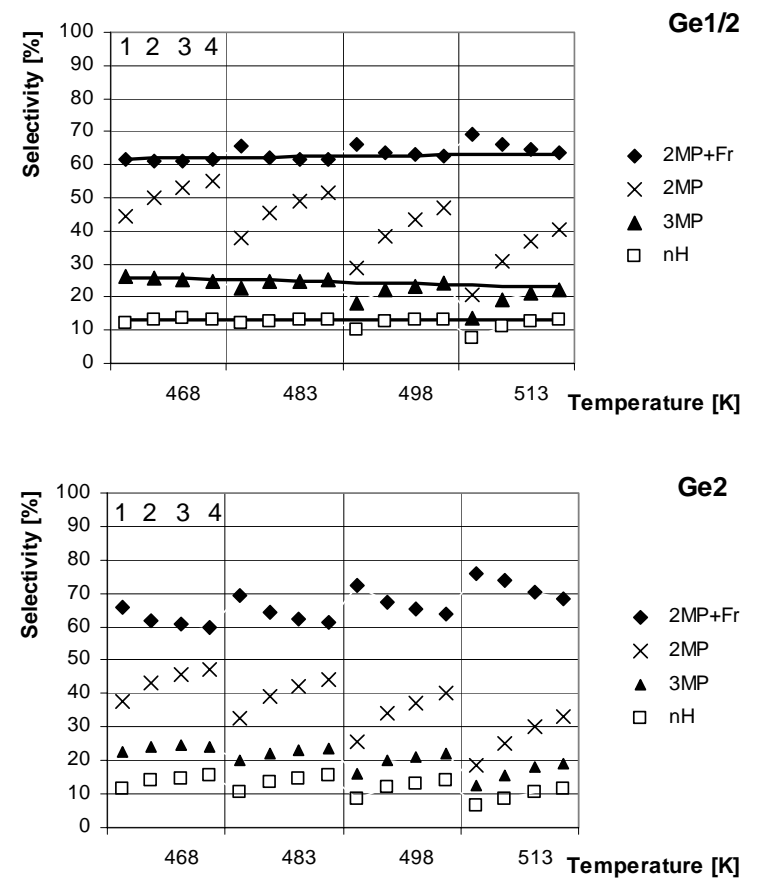

Figure 3: Selectivity comparison for n-hexane, 3methylpentane, 2-methylpentane and 2-methylpentane + fragments from the conversion of MCP on two Rh-Ge catalysts: a, Ge2 b, Ge 1/2. Each temperature includes four increasing hydrogen pressures abbreviated as follows, 1: 120 Torr, 2: 240 Torr, 3: 360 Torr, 4: 480 Torr.

\section{Discussion}

A study of several metal blacks [8] revealed that four metals Pt, Pd, - and to a lesser extent - Ir and Rh were able to catalyze the non-degradative opening of methylcyclopentane. Others as $\mathrm{Co}, \mathrm{Ni}, \mathrm{Ru}$ and Os showed almost exclusively extensive hydrogenolysis, yielding mainly methane. However, small particles of $\mathrm{Ni}$ [25] and $\mathrm{Ru}$ [26] promoted single splitting rather than multiple hydrogenolysis. An opposite behavior was obtained on rhodium: inasmuch as higher ratio of fragments was produced on smaller particles [7]. To explain this behavior of Rh, two factors have to be considered. First, with catalysts of low disper- 
sion, fragments were produced mainly from the 2MP surface intermediate " $2 \mathrm{MP}_{\mathrm{S}}$ ". As the dispersion increased the maximum selectivity of 2MP decreased. This would indicate that particular catalytic sites must exist on small $\mathrm{Rh}$ particles that promote the breaking up of $2 \mathrm{MP}_{\mathrm{S}}$ resulting in fragments. Second, the further hydrogenolysis of $\mathrm{nH}_{\mathrm{S}}$ and $3 \mathrm{MP}_{\mathrm{S}}$ being more favored than their desorption increased also the selectivity of fragmentation on small Rh particles. The three $\mathrm{C}_{6}$ surface ring-opening intermediates are fragmented further nearly with the same probability, independently of the reaction conditions. Thus the $2 \mathrm{MP} / \mathrm{nH}$ ratio remains constant (Table 1). This may be the reason for the higher selectivity of fragments obtained on Parent compared to Blank sample. Further, special catalytic ensembles on small $\mathrm{Rh}$ particles advance multiple hydrogenolysis rather than ring opening. Finally, our results concerning monometallic catalysts are very similar to those previously published [2].

The Rh particle size of the two germanium containing catalysts did not change practically during the preparation procedure [1], only the deposited Ge atoms blocked some of the Rh atoms hampering thus the chemisorption of hydrogen. Therefore their $\mathrm{H} / \mathrm{Rh}$ ratio was lower than that of Parent having the same particle size. Keeping this in mind, we expect that the bimetallic samples would behave as the Parent catalyst. In fact, however, Ge $1 / 2$ gave catalytic patterns closer to those observed on sample Blank (Figures 2b, 3 and Table 1). Previous characterization work [1] based on CO FTIR and catalytic transformation of 2,2,3trimethylbutane permitted us to conclude that special, highcoordination sites were blocked by germanium on sample Ge $1 / 2$. Thus, its peculiar catalytic behavior in MCP conversion is in agreement with the assumption that Ge blocked selectively the active sites suited for multiple hydrogenolysis. The highest activity observed with Ge $1 / 2$ agrees well with this idea considering the higher residence time of deeply dehydrogenated species on the active sites of multiple hydrogenolysis.

On the other hand, the behavior of sample $\mathbf{G e 2}$ is very similar to that observed for the Parent catalyst (see Figure $2 \mathrm{~b}$ and Table 1). Indeed, nonselective deposition of Ge on Rh particles was pointed out in our previous study [1] for Ge2 sample. Thus, active sites for multiple hydro-

\section{References}

[1] L. Pirault-Roy, D. Teschner, Z. Paál, M. Guérin, accepted Appl. Catal. 2002 (Apcata 6465).

[2] B. Coq, F. Figuéras, Coord. Chem. Rev. 178-180 (1998) 1753.

[3] J.L. Margitfalvi, S. Szabó, F. Nagy, Stud. Surf. Sci. Catal. 27 (1986) 373.

[4] J.P. Candy, B. Didillon, E.L. Smith, T.B. Shay, J.M. Basset, J. Mol. Catal. 86 (1994) 179.

[5] J.L. Margitfalvi, I. Borbáth, E. Tfirst, A. Tompos, Catal. Today 43 (1998) 29.

[6] F.G. Gault, Adv. Catal. 30 (1981) 1.

[7] D. Teschner, K. Matusek, Z. Paál, J. Catal. 192 (2000) 335. genolysis must still remain in this case and the catalytic performances were similar to that of the Parent catalyst.

Earlier [7] we observed changes in the mechanism of MCP ring opening occurring in dispersion range of 65$80 \%$. Now we demonstrated that the prevailing route could be altered without modifying the particle size, simply by changing the sites occupied by Ge. Selective deposition of an inactive second metal (Ge) blocked catalytically active sites (low-Miller-index microfacets) suited for the further hydrogenolysis of the surface ring-opening intermediates after the primary opening step.

\section{Conclusions}

1. We observed that the mechanism of MCP ring opening is dispersion dependent for Rh-based catalysts offering a Rh accessibility in the 60-80 $\%$ range, in agreement with our earlier report [7].

2. Blocking low-Miller-index microfacets via Ge deposition caused a significant decrease in the multiple character of hydrogenolysis, not typical for this particular particle size corresponding to $80 \%$ dispersion.

3. We confirmed also by the reaction of MCP, that selective Ge deposition is a new way for modifying catalytic properties, without changing the Rh particle size. It involves a selective poisoning of the catalytically active sites suitable for multiple hydrogenolysis with an inactive deposit: germanium.

\section{Acknowledgement}

D. T. and Z. P. are grateful to the Hungarian National Science Foundation (Grant OTKA T037241) for support.

[8] Z. Paál, P. Tétényi, Nature 267 (1977) 234.

[9] Y. Barron, G. Maire, J.M. Muller, F.G. Gault, J. Catal. 5 (1966) 428.

[10] A. Dauscher, F. Garin, G. Maire, J. Catal. 105 (1987) 233.

[11] Z. Paál, in Z. Paál, P.G. Menon (Eds.), Hydrogen Effects in Catalysis, Dekker, New York, 1988, p. 449.

[12] Z. Paál, J. Mol. Catal. 94 (1994) 225.

[13] H. Zimmer, Z. Paál, J. Mol. Catal. 51 (1989) 261.

[14] D. Teschner, Z. Paál, D. Duprez, Catal. Today 65 (2001) 185.

[15] R. Kramer, M. Fischbacher, J. Mol. Catal. 51 (1989) 247.

[16] K. Hayek, R. Kramer, Z. Paál, Appl. Catal. 162 (1997) 1. 
[17] G. Del Angel, B. Coq, R. Dutartre, F. Figueras, J. Catal. 87 (1984) 27.

[18] B. Coq, R. Dutartre, F. Figueras, T. Tazi, J. Catal. 122 (1990) 438.

[19] J.B.F. Anderson, R. Burch, J. Chem. Soc. Faraday Trans. 83 (1987) 913.

[20] D. Teschner, Z. Paál, React. Kinet. Catal. Lett. 68 (1999) 25.

[21] D. Teschner, L. Oliviero, D. Duprez, Z. Paál, Proc. of XII ${ }^{\text {th }}$ Intern. Cong. on Catal., 2000 Recent Reports No. R077.
[22] D. Teschner, Z. Paál, D. Duprez, J. Mol. Catal. A 179 (2002) 201.

[23] B. Coq, A. Goursot, T. Tazi, F. Figueras, D.R. Salahub, J. Amer. Chem. Soc. 113 (1991) 1485.

[24] Z. Paál, Adv. Catal. 29 (1980) 273.

[25] F.J. Schepers, E.H. van Broekhoven, V. Ponec, J. Catal. 96 (1985) 82.

[26] B. Coq, A. Bittar, F. Figueras, Appl. Catal. 59 (1990) 103. 